\title{
Towards a representation of priming on soil carbon decomposition in the global land biosphere model ORCHIDEE (version 1.9.5.2)
}

\author{
Bertrand Guenet $^{1}$, Fernando Esteban Moyano ${ }^{2}$, Philippe Peylin ${ }^{1}$, Philippe Ciais ${ }^{1}$, and Ivan A Janssens ${ }^{3}$ \\ ${ }^{1}$ Laboratoire des Sciences du Climat et de l'Environnement, LSCE/IPSL, \\ CEA-CNRS-UVSQ, Université Paris-Saclay, 91191 Gif-sur-Yvette, France \\ ${ }^{2}$ Department of Bioclimatology, Georg-August University of Göttingen, \\ Büsgenweg 2, 37077 Göttingen, Germany \\ ${ }^{3}$ Department of Biology, Research Group of Plant and Vegetation Ecology, \\ University of Antwerp, Universiteitsplein 1, 2610 Wilrijk, Belgium \\ Correspondence to: Bertrand Guenet (bertrand.guenet@1sce.ipsl.fr)
}

Received: 11 September 2015 - Published in Geosci. Model Dev. Discuss.: 27 October 2015

Revised: 9 February 2016 - Accepted: 13 February 2016 - Published: 1 March 2016

\begin{abstract}
Priming of soil carbon decomposition encompasses different processes through which the decomposition of native (already present) soil organic matter is amplified through the addition of new organic matter, with new inputs typically being more labile than the native soil organic matter. Evidence for priming comes from laboratory and field experiments, but to date there is no estimate of its impact at global scale and under the current anthropogenic perturbation of the carbon cycle. Current soil carbon decomposition models do not include priming mechanisms, thereby introducing uncertainty when extrapolating short-term local observations to ecosystem and regional to global scale. In this study we present a simple conceptual model of decomposition priming, called PRIM, able to reproduce laboratory (incubation) and field (litter manipulation) priming experiments. Parameters for this model were first optimized against data from 20 soil incubation experiments using a Bayesian framework. The optimized parameter values were evaluated against another set of soil incubation data independent from the ones used for calibration and the PRIM model reproduced the soil incubations data better than the original, CENTURYtype soil decomposition model, whose decomposition equations are based only on first-order kinetics. We then compared the PRIM model and the standard first-order decay model incorporated into the global land biosphere model ORCHIDEE (Organising Carbon and Hydrology In Dynamic Ecosystems). A test of both models was performed at ecosystem scale using litter manipulation experiments from five
\end{abstract}

sites. Although both versions were equally able to reproduce observed decay rates of litter, only ORCHIDEE-PRIM could simulate the observed priming $\left(R^{2}=0.54\right)$ in cases where litter was added or removed. This result suggests that a conceptually simple and numerically tractable representation of priming adapted to global models is able to capture the sign and magnitude of the priming of litter and soil organic matter.

\section{Introduction}

Soils are the largest reservoir of organic carbon (C) on land, holding 3 times as much as plant biomass globally (MEA, 2005). The dynamics of long-term soil organic matter formation (Schmidt et al., 2011) and its decomposition on timescales of future climate change (Jones et al., 2003) both remain poorly understood. The lack of a mechanistic understanding of soil carbon dynamics on timescales going from years to centuries induces important differences in the future projections of the global land carbon storage among global land biosphere models (Todd-Brown et al., 2013).

Different conceptual models have been proposed to explain empirical data on soil carbon decomposition, mainly incubation experiments (Wutzler and Reichstein, 2008; Manzoni and Porporato, 2009). Those conceptual models are usually calibrated to fit data (i.e. measurements of stock evolution or fluxes) from experiments on soil incubation, and on timescales going from hours to days (Panikov and Sizova, 
1996; Blagodatsky and Richter, 1998). It was shown by Wutzler and Reichstein (2008) that conceptual decomposition models accounting for interactions between labile and more recalcitrant microbial-related carbon, often called priming effects, could better fit data from incubation experiments acquired over periods of about 100 days.

The conceptual models of soil carbon decomposition encapsulated in global land biosphere models usually ignore interactions between labile and recalcitrant carbon. All global land biosphere model parts of the Earth system models (ESMs) used for IPCC climate projections are based on donor-pool dominant transfer and first-order decay (Luo et al., 2016). Many of those global land biosphere models have soil carbon modules derived from the CENTURY (Parton et al., 1988) and RothC (Coleman and Jenkinson, 1999) models, in which the first-order decay rates of different pools are modulated by soil temperature and moisture, as well as by soil texture (Friedlingstein et al., 2006).

Although the conceptual models with priming showed a more realistic behaviour than first-order decay models when applied to short-term incubation data, one may still wonder if priming significantly influences the dynamics of soil carbon on timescales ranging from years to decades, and at large spatial scales. On the one hand, incorporating priming in a global land biosphere model has the disadvantage of introducing new parameters that are difficult to constrain and of generating a more complex - but unproven - dynamical behaviour than the first-order decay models. On the other hand, if the performances of first-order decay models are not satisfactory at the large scale, structural changes of soil carbon models are needed and must be carefully tested.

The current situation with first-order decay dynamics in global land biosphere is that out of the 11 Earth system models used for the IPCC-AR5 (Intergovernmental Panel on Climate Change Fifth Assessment Report) CMIP5 (Coupled Model Intercomparison Project) simulations and benchmarked by Todd-Brown et al. (2013) against a global soil organic carbon (SOC) map; only six succeeded in representing the total mean $\mathrm{C}$ stocks at the global scale, but all failed to reproduce the spatial heterogeneity of SOC stocks as well as the SOC distribution under different vegetation cover (Todd-Brown et al., 2013). Possible causes of model failure include not only errors in model structure but also errors in the different parameters controlling soil carbon dynamics. The optimization of the parameters of a first-order decay model against a global SOC map could only partly reduce regional discrepancies with observations, with the optimized model explaining only $41 \%$ of the global variability of SOC (Hararuk et al., 2014). On the other hand, the use of a structurally different model that accounted for microbial biomass was shown to produce a rather realistic large-scale SOC variability, but very different soil carbon dynamics in response to future climate change (Wieder et al., 2013). This illustrates that model structure matters a lot for the simula- tion of the current distribution of soil carbon and its future evolution in response to climate and $\mathrm{CO}_{2}$ changes.

Discrepancies between global land biosphere model predictions and observations are partially due to models lacking key mechanisms controlling SOC dynamics (Schmidt et al., 2011). One example is the interactions with the $\mathrm{N}$ (nitrogen) cycle. The majority of the ESMs used for the IPCC-AR5 CMIP5 Earth System simulations did not represent explicitly the nitrogen cycle, but the two ESMs with an explicit nitrogen cycle also did not result in a better simulations of current SOC (Todd-Brown et al., 2013). Another example is the role of microorganisms. The first-order kinetics used in most models obviates the role that microbial decomposers are known to play in controlling SOC mineralization (Cleveland et al., 2007; Garcia-Pausas and Paterson, 2011), but their activities is controlled by physical and chemical drivers (Kemmit et al., 2008). Therefore, ESMs have significant gaps in reproducing the mechanisms related to microbial dynamics such as priming (see definition below), which is the object of this study.

Soil C priming is defined as a modification of SOC decomposition rates when fresh organic $\mathrm{C}$ (FOC) is added (Kuzyakov et al., 2000). Priming is almost ubiquitously observed in ecosystem studies where organic matter inputs are altered in laboratory incubations (reviewed by Blagodatskaya and Kuzyakov, 2008) or directly on the field (Boone et al., 1998; Borken and Muhs, 2002; Chemidlin-PrévostBouré et al., 2010; Subke et al., 2004; Sulzman et al., 2005; Xiao et al., 2015). Priming can occasionally be negative but most commonly has a stimulative effect on the decomposition of organic matter that decomposes. Several mechanisms may be involved in controlling priming (Fontaine et al., 2003; Blagodatskaya and Kuzyakov, 2008; Guenet et al., 2010b), and conceptual models of priming can have a substantial number of parameters making their parameterization quite complex at large scales (Wutzler and Reichstein, 2013). Wutzler and Reichstein (2008) proposed conceptual models summarized into different equations to introduce priming without using too many parameters, but in all cases an explicit representation of microbial biomass was required. Recently, Guenet et al. (2013a) modified the equation proposed by Wutzler and Reichstein (2008) to represent priming without an explicit representation of microbial biomass, assuming that microbial biomass is always at equilibrium with FOC. This assumption is suitable for being incorporated into ESMs since it adds only one more free parameter compared to the first-order kinetic models. This priming scheme was incorporated into the global land biosphere model ORCHIDEE (Organising Carbon and Hydrology In Dynamic Ecosystems), with the priming parameters statistically calibrated to reproduce the same equilibrium state (in terms of $\mathrm{C}$ stocks, after spin-up of the model) than the standard version based on CENTURY (Guenet et al., 2013b). Despite its calibration ensuring the same initial state of SOC for England and Wales, the version of ORCHIDEE with priming resulted in a loss of 

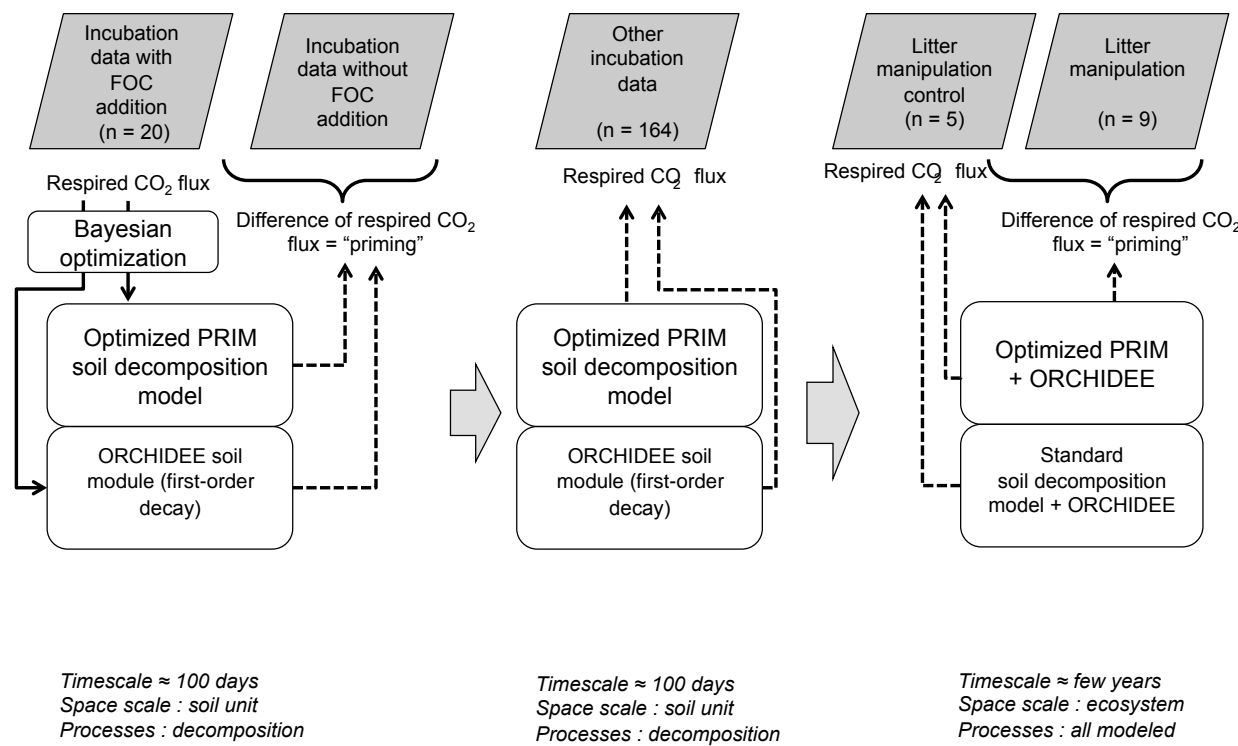

Figure 1. Summarizing scheme of the methods.

SOC during the late 20th century, in better agreement with inventory data (Bellamy et al., 2005) than the standard version, which produced a continuous SOC gain. In that study, however, the parameters of the priming model were not based on observations but tuned instead to equilibrium SOC values. The objectives of this study are, therefore,

- to derive optimal parameter values of a priming model (PRIM) with $\mathrm{C}$ inputs forced by data by using a Bayesian method (Tarantola, 1987) with priors and data from 20 different soil incubations;

- to introduce the calibrated PRIM model into the ORCHIDEE ecosystem model version AR5 and evaluate the new version ORCHIDEE-PRIM against independent in situ litter manipulation experiments at ecosystem scale;

- to assess if the priming model significantly improves the simulation of SOC mineralization compared to the standard first-order decay model used in ORCHIDEE, on timescales of months to years.

\section{Materials and methods}

The material and methods section is summarized in Fig. 1.

\subsection{Models presentation}

\subsubsection{Soil carbon priming model PRIM}

To represent priming, we used the ORCHIDEE soil decomposition module, which is based on the carbon-related mod- ules of CENTURY (Parton et al., 1988). It has three carbon pools (active, slow, and passive) and two litter pools (metabolic and structural). SOC decomposition is modulated by soil temperature and moisture functions. Active SOC decomposition is further modulated by a clay function. These functions are the same as in CENTURY but they are driven by soil physical variables calculated at a daily time step by the soil physics of ORCHIDEE (Krinner et al., 2005). The transfers among pools are described using the CENTURY equations with similar parameters (Parton et al., 1988). In the PRIM model, we replaced the CENTURY decomposition equations by those developed by Guenet et al. (2013a) to simulate a priming effect:

$$
\begin{aligned}
& \frac{\mathrm{dSOC}_{\text {Active }}}{\mathrm{d} t}=I-k_{\mathrm{SOC}_{\text {Active }}} \times \mathrm{SOC} \\
& \times\left(1-e^{-c \times\left(\text { Litter_C }_{-}\right)}\right) \times \theta \times \tau \times \gamma, \\
& \frac{\mathrm{dSOC}_{\text {Slow }}}{\mathrm{d} t}=I-k_{\mathrm{SOC}_{\text {Slow }}} \times \mathrm{SOC} \\
& \times\left(1-e^{-c \times\left(\text { Litter_C}_{-}+\text {SOC }_{\text {Active }}\right)}\right) \times \theta \times \tau, \\
& \frac{\mathrm{dSOC}_{\text {Passive }}}{\mathrm{d} t}=I-k_{\mathrm{SOC}_{\text {Passive }}} \times \mathrm{SOC} \\
& \times\left(1-e^{-c \times\left(\text { Litter_C }_{-}+\mathrm{SOC}_{\text {Active }}+\mathrm{SOC}_{\text {Slow }}\right)}\right) \\
& \times \theta \times \tau,
\end{aligned}
$$

where $I$ is the input of $\mathrm{C}$ into the pool considered, $k_{\mathrm{SOC}}$ the SOC decomposition rate for the active, the slow, and the passive pool, and Litter_C the sum of all the litter pools of the model. $\theta, \tau$, and $\gamma$ are the soil moisture function, the temperature function, and the clay function modulating decomposi- 
tion, respectively. $c$ is a parameter controlling the impact of the FOC pool on the SOC mineralization rate. Here, we considered that FOC represents all the carbon from pools more labile than the pool being affected as shown in Eqs. (1)-(3). Therefore, FOC is only litter for the active SOC pool, but for the slow SOC pool, FOC is the sum of the litter and the active SOC pool. Finally, for the passive SOC pool, FOC is the litter and the active and slow carbon pools. The decomposition of the first donor litter pool is described using first-order kinetics (Eq. 4):

$\frac{\mathrm{dLitter} \_\mathrm{C}}{\mathrm{d} t}=I-k_{\text {Litter_C }} \times$ Litter_C $\times \theta \times \tau$.

In the Wutzler and Reichstein (2008) equation, the SOC mineralization was described by

$\frac{\mathrm{dSOC}}{\mathrm{d} t}=I-k_{\mathrm{SOC}} \times \mathrm{SOC} \times\left(1-e^{-c \times \mathrm{MB}}\right)$,

where MB is the microbial biomass. Unlike Wutzler and Reichstein (2008), our model does not explicitly simulate MB but assumes that MB equilibrates with FOC; thus, the relationship between MB and FOC is linear. Consequently, we represent priming using a direct relationship between FOC and SOC mineralization. Finally, the moisture, temperature, and clay functions are described by Eqs. (6), (7), and (8), respectively, with soil_moisture in $\mathrm{m}^{3} \mathrm{H}_{2} \mathrm{O} \mathrm{m}^{-3}$ of soil, soil_temperature in Kelvin and clay in \% wt:

$$
\begin{aligned}
\theta= & \max \left(0.25, \min \left(1,-1.1 \times \text { soil_moisture }{ }^{2}\right.\right. \\
& +2.4 \times \text { soil_moisture }+0.29)), \\
\tau= & \exp (0.69 \times(\text { soil_temperature }-303) / 10), \\
\gamma= & 1-0.75 \times \text { clay. }
\end{aligned}
$$

The flux of decomposed carbon of the $i$ th pool is then split into different fluxes following Eqs. (9) and (10) between respired carbon $\left(\right.$ resp $\left._{i}\right)$ and recycled carbon (recy).

$\operatorname{resp}_{i}=\left(1-\sum_{\text {pools }} f_{i, \text { pools }}\right) \times$ decomposed_carbon $i$,

$C_{i \rightarrow j}=f_{i, j} \times$ decomposed_carbon ${ }_{i}$,

where decomposed_carbon is the second terms of Eqs. (1) to (5), $f_{i, j}$ a set of parameters controlling the flux from pool $i$ to the pool $j$ and $C_{i \rightarrow j}$ being the flux from the pool $i$ to $j$. The values of the $f$ parameters are similar to Parton et al. (1988).

\subsubsection{ORCHIDEE and ORCHIDEE-PRIM}

ORCHIDEE is a process-based global land biosphere model that calculates the fluxes of $\mathrm{CO}_{2}, \mathrm{H}_{2} \mathrm{O}$, and heat between the terrestrial land and the atmosphere. The time step of the model is in half-hourly, and the variations of $\mathrm{H}_{2} \mathrm{O}$ and $\mathrm{C}$ pools are calculated on a daily basis. The model has been evaluated at different scales (sites, regions, globes) and under different climates from the tropics to northern boreal zones (Krinner et al., 2005; Ciais et al., 2005; Santaren et al., 2007; Piao et al., 2006). ORCHIDEE results from the coupling of three different sub-models. The first one is called SVAT SECHIBA (Schématisation des EChangesHydriques à l'Interface entre la Biosphère et l'Atmosphère) and describes soil water budget and turbulent fluxes of energy and water between the atmosphere and the biosphere (Ducoudré et al., 1993; de Rosnay and Polcher, 1998). The second one is derived from the dynamic global vegetation model LundPostdam-Jena (LPJ) (Sitch et al., 2008) and deals with vegetation dynamics (fire, sapling establishment, light competition, tree mortality, and climatic criteria for the introduction or elimination of plant functional types). The last, called STOMATE (Saclay-Toulouse-Orsay Model for the Analysis of Terrestrial Ecosystems) deals with phenology and carbon dynamics of the terrestrial biosphere. Twelve plant functional types (PFT) are used to classify the vegetation. Each PFT dynamic is controlled by similar set of governing equations but using different parameter values. Only the leafy season onset and offset, are PFT specific (Krinner et al., 2005).

The simulation of SOC in ORCHIDEE version is based on CENTURY (Parton et al., 1988) as described above. No vertical description of the SOC is included in the ORCHIDEE version used here. In ORCHIDEE-PRIM we replaced CENTURY by the PRIM model described in Sect. 2.1.1.

\subsection{Data description}

\subsubsection{Incubation experiments to calibrate the priming model}

We optimized the PRIM parameters and the ORCHIDEE soil module parameters using data from soil incubation experiments where FOC was added and the priming effect was measured by comparing a control study without FOC with a perturbation study with FOC (Table 1). The data come from 20 incubations (from nine studies) of duration going from 1 week to 10 months. The incubated soil samples have very different characteristics (Table 1) and came from different ecosystems (grassland, cropland, broadleaf forest, needleleaf forest, savannah). However, the great majority of the data used to optimize the model were obtained from temperate soils. In the incubation experiments, added FOC was labelled with ${ }^{13} \mathrm{C}$ or ${ }^{14} \mathrm{C}$ and therefore the respired $\mathrm{CO}_{2}$ fluxes coming from either SOC already present before the FOC amendments or from the FOC induced priming of SOC pools was estimated separately. We used only incubations performed during at least 7 days to eliminate all studies that potentially observed apparent priming effects. Apparent priming is a replacement of the ${ }^{12} \mathrm{C}$ in microbial biomass with labelled carbon isotopes, a short-term artefact due to the amendment of labelled material to an unlabelled soil (Blagodatskaya and 


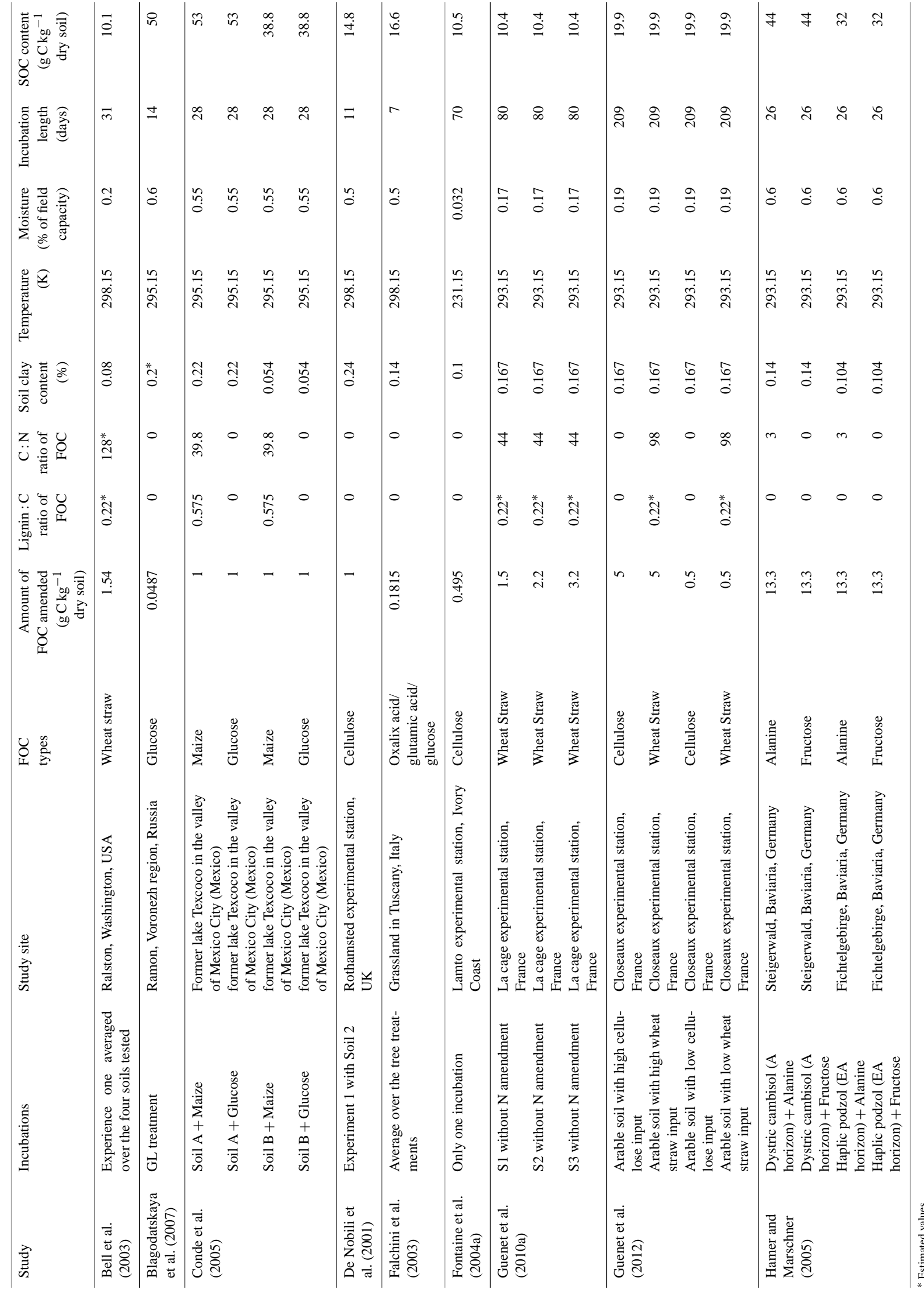


Kuzyakov, 2008). Moreover, we used only studies that reported cumulative-respired $\mathrm{CO}_{2}$ fluxes in order to optimize the priming parameters against the extra $\mathrm{CO}_{2}$ fluxes obtained at the end of the experiment and not those resulting from short-term priming dynamics, since cumulative mineralization integrates the different processes occurring during incubation. Finally, several treatments might be performed in the studies used to optimize the model (different soils, different types and amount of FOC). On the one hand, when the treatments performed differed on aspects reproducible by the model (amounts of FOC added, different clay content in the soils used, etc.) we considered all the treatments. On the other hand, we averaged the results of the different treatments to perform the optimization except in case where the treatments clearly impact the results without the possibility to reproduce the experimental design with the model (addition of mineral $\mathrm{N}$ for instance).

We also use the control incubations without FOC amendments to evaluate both models. We extracted data from the figures of original publications (Table 1) using GraphClick version 3.0. Several input variables are needed to run the soil model, as described in Sect. 2.1.1. When data were not available from the surveyed publications, we obtained them from the databases normally used for running ORCHIDEE, except for the $\mathrm{C}: \mathrm{N}$ ratio of $\mathrm{FOC}$ and for clay content where data came from Rodale et al. (1960) and from USDA (https: //soilseries.sc.egov.usda.gov/), respectively. The three carbon pools of CENTURY are not measurable (Six et al., 2002), so we cannot estimate how much $\mathrm{C}$ in each pool is present in the incubated samples. To calculate the distribution of $\mathrm{C}$ among the three pools of the model, we ran ORCHIDEE until equilibrium was reached at the sites where soil samples were taken and calculated the percentage of each pool.

\subsubsection{Incubation data used for evaluation of the priming model}

A first evaluation of the soil carbon model with and without priming is performed at the scale of soil samples against independent data from the large database of soil incubations (300 in total) published by Moyano et al. (2012). Within this database we selected the experiments where all the inputs necessary to run the two soil carbon models were available (clay, content, moisture, temperature, SOC content at the beginning of the incubation) and where cumulative mineralization or mineralization rates associated with the time step between two measurements were reported. We removed all the studies without information on the location since geographical coordinates are necessary to run ORCHIDEE and thus estimate the initial fraction of each pool. We selected only data coming from experiments without important soil manipulation (e.g. compaction, litter amendments). The model evaluation was performed against a set of 164 independent incubation experiments.

\subsubsection{Ecosystem-level data used for evaluation of the priming model}

A second evaluation of the ORCHIDEE-PRIM model was performed at ecosystem scale against observations of four litter manipulation experiments (Boone et al., 1998; Chemidlin-Prévost-Bouré et al., 2010; Subke et al., 2004; Sulzman et al., 2005) and one compost amendment experiment (Borken and Muhs, 2002). In the litter experiments, two treatments and a control are generally performed. The treatments are total exclusion of above ground litter using nets to prevent fresh litter from falling onto the soil, often transplanting the collected fresh litter to create a second treatment with doubled aboveground litter inputs (Boone et al., 1998; Chemidlin-Prévost-Bouré et al., 2010; Sulzman et al., 2005). For the compost amendment experiment by Borken and Muhs (2002), $1.4 \mathrm{~kg} \mathrm{C} \mathrm{m}^{-2}$ (and a zero-addition control) of compost was added to the soil. These studies are presented in Table 3. When information about soil clay content was not available in the original study, we extracted it from Zobler (1986). The data measured at field scale are not only the soil $\mathrm{CO}_{2}$ efflux including the heterotrophic respiration but also root respiration in the same flux without clear separation of the two components.

\subsection{Optimization procedure}

For PRIM, the six parameters optimized are turnover rate $\left(k_{\mathrm{SOC}}\right)$ and priming parameters $c$ for each of the three pools (Table 2). For the ORCHIDEE soil module, only the three $k_{\text {SOC }}$ values are optimized. The same parameters are optimized against the priming incubations data set described in Sect. 2.2.1. Since optimizations were performed using soil incubations data obtained at optimal temperature and soil moisture, we did not optimize the parameters related to Eqs. (6) and (7) because the range of observations was quite limited. Optimization was performed in the framework of the Bayesian inversion method with priors (Tarantola, 1987) as described by Santaren et al. (2007) assimilating all data streams in the same cost function. Assuming that all uncertainties follow Gaussian distributions (parameter error, measurement error, model error), the optimized parameters correspond to a set minimizing the following quadratic cost function:

$$
\begin{aligned}
J(\boldsymbol{x})= & \frac{1}{2}\left[(\boldsymbol{y}-\mathbf{H}(\boldsymbol{x}))^{t} \mathbf{R}^{-1}(\boldsymbol{y}-\mathbf{H}(\boldsymbol{x}))\right. \\
& \left.+\left(\boldsymbol{x}-\boldsymbol{x}_{b}\right)^{t} \mathbf{P}_{b}^{-1}\left(\boldsymbol{x}-\boldsymbol{x}_{b}\right)\right] .
\end{aligned}
$$

The cost function defined by Eq. (11) contains both the mismatch between model outputs and observed data, and the mismatch between optimized parameters and the prior values. The mismatch is weighted by errors of each quantity. $\boldsymbol{x}$ is the of unknown parameters vector, $\boldsymbol{x}_{b}$ the prior values, $\boldsymbol{y}$ the observations vector, and $\mathbf{H}(x)$ the model outputs. $\mathbf{P}_{b}$ is the prior parameter error variances/covariances, and $\mathbf{R}$ contains 
Table 2. Model parameters summary for PRIM and the ORCHIDEE soil module.

\begin{tabular}{|c|c|c|c|c|c|}
\hline $\begin{array}{l}\text { Model } \\
\text { parameter }\end{array}$ & Meaning & $\begin{array}{l}\text { SOC } \\
\text { pools }\end{array}$ & $\begin{array}{l}\text { Prior } \\
\text { range }\end{array}$ & $\begin{array}{l}\text { Posterior modes } \pm \text { SD } \\
\text { (prior modes) for PRIM }\end{array}$ & $\begin{array}{l}\text { Posterior modes } \pm \mathrm{SD} \\
\text { (prior modes) for the } \\
\text { ORCHIDEE soil module }\end{array}$ \\
\hline $\mathrm{k}_{\mathrm{SOC}}$ & $\begin{array}{l}\text { Turnover rate } \\
\text { of SOM (d) }\end{array}$ & $\begin{array}{l}\text { Active } \\
\text { Slow } \\
\text { Passive }\end{array}$ & $\begin{array}{r}10^{-3}-0.5 \\
0.5-5 \\
5-500\end{array}$ & $\begin{array}{r}0.30 \pm 0.15(0.31) \\
1.12 \pm 0.01(4.51) \\
462.0 \pm 233.8(467.55)\end{array}$ & $\begin{array}{r}0.43 \pm 0.22(0.43) \\
0.50 \pm 0.09(2.39) \\
40.17 \pm 22.19(44.39)\end{array}$ \\
\hline$c$ & $\begin{array}{l}\text { Influence of the FOM } \\
\text { carbon pool in the SOM } \\
\text { mineralization (priming } \\
\text { parameter) }\end{array}$ & $\begin{array}{l}\text { Active } \\
\text { Slow } \\
\text { Passive }\end{array}$ & $\begin{array}{l}2 \times 10^{-4}-500 \\
2 \times 10^{-4}-500 \\
2 \times 10^{-4}-500\end{array}$ & $\begin{array}{r}493.7 \pm 246.8(493.7) \\
194.0 \pm 97.0(194.0) \\
136.5 \pm 68.3(136.5)\end{array}$ & $\begin{array}{l}\mathrm{n} / \mathrm{a} \\
\mathrm{n} / \mathrm{a} \\
\mathrm{n} / \mathrm{a}\end{array}$ \\
\hline
\end{tabular}

the observational error variances/covariances, which represents both measurement uncertainty and model uncertainty.

To minimize the cost function, we used a gradient-based iterative algorithm, called L-BFGS-B (limited-memory Broyden-Fletcher-Goldfarb-Shanno algorithm) (Zhu et al., 1995). A range of values for all the parameters is prescribed by calling L-BFGS-B. At each iteration, the cost function $J(\boldsymbol{x})$ gradient is calculated, with respect to the six parameters. When $J(\boldsymbol{x})$ is minimized, using a classic finite difference method, we further calculated the posterior error covariance matrix on the parameters $\mathbf{P}_{a}$ from the prior error covariance matrices and the Jacobian of the model at the minimum of the cost function, using the linearity assumption (Tarantola, 1987). When error correlations are close to 1 it suggests that the observations do not permit one to clearly separate the effect of two parameters.

The model $\mathbf{H}(\boldsymbol{x})$ is non-linear and therefore the approach to minimize the cost function is sensitive to potential local minima. We get around this by performing 30 optimizations with different sets of prior parameters randomly distributed within their variation range. We then used the case providing the lowest cost function. This approach drastically reduces the sensitivity to potential local minima as illustrated in Santaren et al. (2014).

We defined the prior ranges of decomposition rates using literature data (Parton et al., 1988; Gignoux et al., 2001). However, only two studies already estimated the $c$ parameter before (Guenet et al., 2013a, b), its prior value is therefore considered as non-informative and we set a large error on the prior $(50 \%)$. As for the variance of the model-data mismatch term in the cost function of Eq. (11), note that with our formalism this error should include both the model error (for instance the model capability to represent the measurement) and the measurement error. Given that the error on the measurements was difficult to estimate precisely for each study, we fixed it to $5 \%$ of the mean observed $\mathrm{CO}_{2}$ flux assuming that all incubation data were independent. At its minimum, $J(\boldsymbol{x})$ should be close to half the number of observations (reduced $\chi^{2}$ of one). We assumed that all errors (the observations and on the a priori parameters) are uncorrelated.

\subsection{Simulations protocol}

\subsubsection{Simulation protocol for the soil priming model PRIM}

Simulations were performed for each incubation experiment presented in Sect. 2.2.1 (Table 1) as well as for the evaluation sites in Sect. 2.2.2. The simulations of the stand-alone PRIM carbon model (i.e. unplugged from the ORCHIDEE full ecosystem model) were run at a daily time step using FOC inputs from Table 1 or from the Moyano et al. (2012) database. No spin-up was performed. We started the simulation by prescribing to the soil carbon models with and without priming an initial amount of SOC equal to that measured in the study considered, distributed among active, slow, and passive pools as explained in Sect. 2.2.1. At each time step we increment the cumulative heterotrophic respiration coming from SOC mineralization, so that this cumulative simulated $\mathrm{CO}_{2}$ flux can be compared to data from the end of the incubation experiment. Simulations were performed using R 3.0.2.

\subsubsection{Simulation protocol for ORCHIDEE-PRIM and ORCHIDEE}

We ran ORCHIDEE and ORCHIDEE-PRIM at each litter manipulation site presented in Table 3 using 6-hourly climate data obtained from the combination of two existing data sets: the Climate Research Unit (CRU) (Mitchell et al., 2004) and the National Centers for Environmental Prediction (NCEP) (Kalnay et al., 1996). Both models were run using the first 10 years of the climate forcing (1901-1909) repeated in a loop, and an atmospheric $\mathrm{CO}_{2}$ value corresponding to the year 1901 . When the simulated relative yearly change of the SOC stock was less than $0.01 \%$, we considered that a SOC equilibrium was reached. Once pre-industrial equilibrium was reached in each grid point, we ran transient simulations from 1901 until the beginning of the manipulation experiment assuming no land use change driven by reconstructed climate and observed $\mathrm{CO}_{2}$. Then when the simulation reached the year at which the litter manipulation ex- 
Table 3. Description of the studies used to evaluate the model.

\begin{tabular}{|c|c|c|c|c|c|c|c|c|}
\hline Study & $\begin{array}{l}\text { Treatments } \\
\text { performed }\end{array}$ & Ecosystems & $\begin{array}{l}\text { Sites names } \\
\text { (coordinates) }\end{array}$ & $\begin{array}{l}\text { Treatment } \\
\text { performed } \\
\text { in }\end{array}$ & $\begin{array}{l}\mathrm{CO}_{2} \\
\text { monitored } \\
\text { between }\end{array}$ & $\begin{array}{r}\text { Soil clay } \\
\text { content } \\
(\%)\end{array}$ & $\begin{array}{r}\text { Soil silt } \\
\text { content } \\
(\%)\end{array}$ & $\begin{array}{r}\text { Soil sand } \\
\text { content } \\
(\%)\end{array}$ \\
\hline $\begin{array}{l}\text { Boone et al. } \\
\text { (1998) }\end{array}$ & $\begin{array}{l}\text { No litter/ } \\
\text { double litter/ } \\
\text { control }\end{array}$ & $\begin{array}{l}\text { Deciduous } \\
\text { forest }\end{array}$ & $\begin{array}{l}\text { Harvard forest, } \\
\text { Petersham, } \\
\text { Massachusetts, USA } \\
\left(42^{\circ} 30^{\prime} \mathrm{N}, 72^{\circ} 12^{\prime} \mathrm{W}\right)\end{array}$ & $\begin{array}{l}\text { January } \\
1990\end{array}$ & $\begin{array}{l}\text { June } 1994- \\
\text { June } 1995\end{array}$ & $25^{*}$ & $30^{*}$ & $45^{*}$ \\
\hline $\begin{array}{l}\text { Borken and } \\
\text { Muhs (2002) }\end{array}$ & $\begin{array}{l}\text { Compost } \\
\text { amendment/ } \\
\text { control }\end{array}$ & $\begin{array}{l}\text { Needleleaf } \\
\text { forest }\end{array}$ & $\begin{array}{l}\text { Solling, Norway } \\
\left(51^{\circ} 46^{\prime} \mathrm{N}, 9^{\circ} 34^{\prime} \mathrm{E}\right)\end{array}$ & $\begin{array}{l}\text { August } \\
1997\end{array}$ & $\begin{array}{l}\text { September 1997- } \\
\text { December } 1999\end{array}$ & 3 & 23 & 74 \\
\hline $\begin{array}{l}\text { Chemidlin- } \\
\text { Prévost-Bouré } \\
\text { et al. (2010) }\end{array}$ & $\begin{array}{l}\text { No litter/ } \\
\text { double litter/ } \\
\text { control }\end{array}$ & $\begin{array}{l}\text { Deciduous } \\
\text { forest }\end{array}$ & $\begin{array}{l}\text { Barbeau National } \\
\text { Forest, France } \\
\left(48^{\circ} 29^{\prime} \mathrm{N}, 02^{\circ} 47^{\prime} \mathrm{E}\right)\end{array}$ & $\begin{array}{l}\text { March } \\
2006\end{array}$ & $\begin{array}{l}\text { May 2006- } \\
\text { March } 2007\end{array}$ & 19.3 & 38.8 & 41.9 \\
\hline $\begin{array}{l}\text { Subke et al. } \\
\text { (2004) }\end{array}$ & $\begin{array}{l}\text { Double litter/ } \\
\text { control }\end{array}$ & $\begin{array}{l}\text { Needleleaf } \\
\text { forest }\end{array}$ & $\begin{array}{l}\text { Wetzstein, } \\
\text { Thüringisches } \\
\text { Schiefergebirge, } \\
\text { Germany } \\
\left(50^{\circ} 30^{\prime} \mathrm{N}, 11^{\circ} 10^{\prime} \mathrm{E}\right)\end{array}$ & $\begin{array}{l}\text { April } \\
2002\end{array}$ & $\begin{array}{l}\text { April } 2002 \\
\text { ( } 3 \text { weeks } \\
\text { after treatment)- } \\
\text { October } 2002\end{array}$ & $70^{*}$ & $18^{*}$ & $12^{*}$ \\
\hline $\begin{array}{l}\text { Sulzman et al. } \\
(2005)\end{array}$ & $\begin{array}{l}\text { No litter/ } \\
\text { double litter/ } \\
\text { control }\end{array}$ & $\begin{array}{l}\text { Needleleaf } \\
\text { forest }\end{array}$ & $\begin{array}{l}\text { H. J. Andrews } \\
\text { Experimental Forest, } \\
\text { Oregon, USA } \\
\left(44^{\circ} 15^{\prime} \mathrm{N}, 122^{\circ} 10^{\prime} \mathrm{W}\right)\end{array}$ & $\begin{array}{l}\text { January } \\
1997\end{array}$ & $\begin{array}{l}\text { July } 2001- \\
\text { December } 2003\end{array}$ & $25^{*}$ & $30^{*}$ & $45^{*}$ \\
\hline
\end{tabular}

* Estimated values.

periment began, we modified the input of aboveground litter in the same proportion as in the actual manipulation experiments. Finally, we ran the model for each treatment during a period corresponding to duration of each experiment.

\subsection{Model evaluation}

The model evaluation was performed in two steps. First, we evaluated separately PRIM and the standard first-order decay model with their optimized parameters, as standalone decomposition models, i.e. unplugged from the ORCHIDEE ecosystem model. To evaluate the stand-alone soil models, we used incubation data coming from Moyano et al. (2012) as described in Sect. 2.2.2. Second, we evaluated ORCHIDEE and ORCHIDEE-PRIM against litter manipulation experiments (see Sect. 2.2.3).

To compare model outputs with data we used different metrics. First a linear-mixed effect model with an intercept value forced to zero using model outputs as the variable to explain, and data as the fixed effect and the study where data came from as the random effect. This approach aimed to take into account the fact that incubations performed within the same study are not independent because they were performed and analysed by the same team. The linear-mixed effect model gives the slope of the relationship as output. A slope close to 1 indicates that the model reproduces the data well. Then, we used the normalized standard deviation (NSD) or ratio of model to observed standard deviations; $\mathrm{NSD}=1$ means that the model perfectly reproduces the ob- served standard deviations across experiments:

$\mathrm{NSD}=\frac{\sqrt{\frac{1}{n} \times \sum_{i=1}^{n}\left(x_{i}-\bar{x}\right)^{2}}}{\sqrt{\frac{1}{n} \times \sum_{i=1}^{n}\left(o_{i}-\bar{o}\right)^{2}}}$,

where $x$ refers to the model value, $o$ to the observed value, and $n$ the number of samples. Finally, we compared model performance using the Bayesian information criterion (BIC) taking into account that the PRIM soil model has three more priming parameters (one per pool) than the standard model:

$\mathrm{BIC}=\log (\mathrm{MSD}) \times n+\log (n) \times p$,

where MSD is the mean squared deviation derived from Eq. (14), $n$ the number of data used to evaluate the model, and $p$ the number of parameters of the soil model.

$\operatorname{MSD}=\frac{\sum(m-o)^{2}}{n}$,

where $o$ is the observed values, $m$ the values calculated by the model, and $n$ the number of observations. The lowest is the BIC the better the model is. 
Table 4. Correlation between optimized parameters for (a) PRIM and (b) the ORCHIDEE soil module.

\begin{tabular}{|c|c|c|c|c|c|c|c|}
\hline \multirow[t]{2}{*}{ (a) } & & \multicolumn{3}{|c|}{$k_{\mathrm{soc}}$} & \multicolumn{3}{|c|}{$c$} \\
\hline & & Active & Slow & Passive & Active & Slow & Passive \\
\hline \multirow[t]{3}{*}{$k_{\text {soc }}$} & Active & 1.00 & $1.1 \times 10^{-4}$ & $2.4 \times 10^{-5}$ & $7.3 \times 10^{-5}$ & $6.7 \times 10^{-4}$ & $3.2 \times 10^{-4}$ \\
\hline & Slow & $1.1 \times 10^{-4}$ & 1.00 & $-2.1 \times 10^{-2}$ & $3.1 \times 10^{-5}$ & $8.5 \times 10^{-5}$ & $-3.8 \times 10^{-4}$ \\
\hline & Passive & $2.4 \times 10^{-5}$ & $-2.1 \times 10^{-2}$ & 1.00 & $-8.2 \times 10^{-5}$ & $7.6 \times 10^{-4}$ & $5.3 \times 10^{-4}$ \\
\hline \multirow[t]{3}{*}{$c$} & Active & $7.3 \times 10^{-5}$ & $3.1 \times 10^{-5}$ & $-8.2 \times 10^{-5}$ & 1.00 & $-1.2 \times 10^{-5}$ & $2.9 \times 10^{-4}$ \\
\hline & Slow & $6.7 \times 10^{-4}$ & $8.5 \times 10^{-5}$ & $7.6 \times 10^{-4}$ & $-1.2 \times 10^{-5}$ & 1.00 & $9.6 \times 10^{-4}$ \\
\hline & Passive & $3.2 \times 10^{-4}$ & $-3.8 \times 10^{-4}$ & $5.3 \times 10^{-4}$ & $2.9 \times 10^{-4}$ & $9.6 \times 10^{-4}$ & 1.00 \\
\hline
\end{tabular}

\begin{tabular}{llrrr}
\hline (b) & & \multicolumn{3}{c}{$k_{\text {soc }}$} \\
\cline { 3 - 5 } & & Active & Slow & Passive \\
\hline \multirow{2}{*}{$k_{\text {soc }}$} & Active & 1.00 & $7.2 \times 10^{-5}$ & $3.8 \times 10^{-5}$ \\
& Slow & $7.2 \times 10^{-5}$ & 1.00 & $-1.5 \times 10^{-2}$ \\
& Passive & $3.8 \times 10^{-5}$ & $-1.5 \times 10^{-2}$ & 1.00 \\
\hline
\end{tabular}

\section{Results}

\subsection{Optimized parameters of the priming model}

The parameters obtained after optimization using incubation data described in Sect. 2.2.1 are given in Table 2. The turnover times ranged from a few months $(0.30 \pm 0.15$ year) for the active pool to $462.0 \pm 233.8$ years for the passive pool, the slow pool being intermediate with $1.12 \pm 0.01$ years. The priming parameters indicated a decreasing sensitivity with increasing turnover time. The parameter $c$ values were $493.7 \pm 246.8,194.0 \pm 97.0$, and $136.5 \pm 68.3$ for the active, slow, and passive pools, respectively. Errors correspond to the estimates from the linear assumption at the minimum of $J(\boldsymbol{x})$. For both, the correlation between parameters was low (Table 4) suggesting that the data set used to optimize the parameters covers a large range of situations. We used soil respiration data obtained after incubations of very different time lengths (few days to few months) disentangling the effect of each parameter.

After optimization, both models with and without priming parameterization were able to reproduce the cumulative mineralization measured in the different incubations where FOC was added well (Fig. 2, top panel). The slope of the linear regression between optimized model output and incubation measurements was 1.13 for PRIM and 0.93 for the ORCHIDEE soil module. The NSD value (1.80 and 1.52 for PRIM and the standard soil module, respectively) showed that the models overestimated the variance after optimization. When both models were evaluated against the same incubation experiments but without the addition of FOM, the PRIM model slightly overestimated accumulated mineralization (Fig. 2 middle panel), as indicated by the value of the slope (1.05). Nevertheless, it performed better than the standard soil module, which underestimated the soil mineraliza- tion as indicated by the value of the slope (0.72). The PRIM soil model reproduced quite well the observed priming effect (Sect. 2.2.1) as shown in Fig. 2 (lower panel) with a slope value (1.07). PRIM largely overestimated, however, the variance of data as indicated by the NSD value (3.14). As expected, the standard soil module was totally unable to reproduce priming (Fig. 2, lower panel).

\subsection{Standard soil module vs. PRIM against incubations data}

To evaluate the performance of PRIM, we tested it against data from soil incubation experiments independent from those used for optimization (see Sect. 2.2.2). We did the same with the standard soil module (Fig. 3). The standard soil module tended to overestimate accumulated mineralization as indicated by a slope value of 1.32 and to underestimate the cross-experiments variance by more than $50 \%$ $(\mathrm{NSD}=0.44)$. PRIM performed slightly better, but underestimated accumulated mineralization (slope 0.80 ). The optimized PRIM underestimated the variance by $29 \%$, but the NSD value (0.71) was closer to 1 compared to the standard model. Using the BIC index, which takes into account the higher number of parameters of PRIM, this model still performed better (BIC values of 546.2 vs. 347.4 for standard and PRIM, respectively).

\subsection{ORCHIDEE vs. ORCHIDEE-PRIM comparison using in situ data sets}

When tested at ecosystem-level against litter manipulation experiments, four studies multiplied by three treatments and one study with two treatments. Both ORCHIDEE and ORCHIDEE-PRIM performed generally well to reproduce the soil $\mathrm{CO}_{2}$ efflux (Fig. 4). Generally, both versions showed 

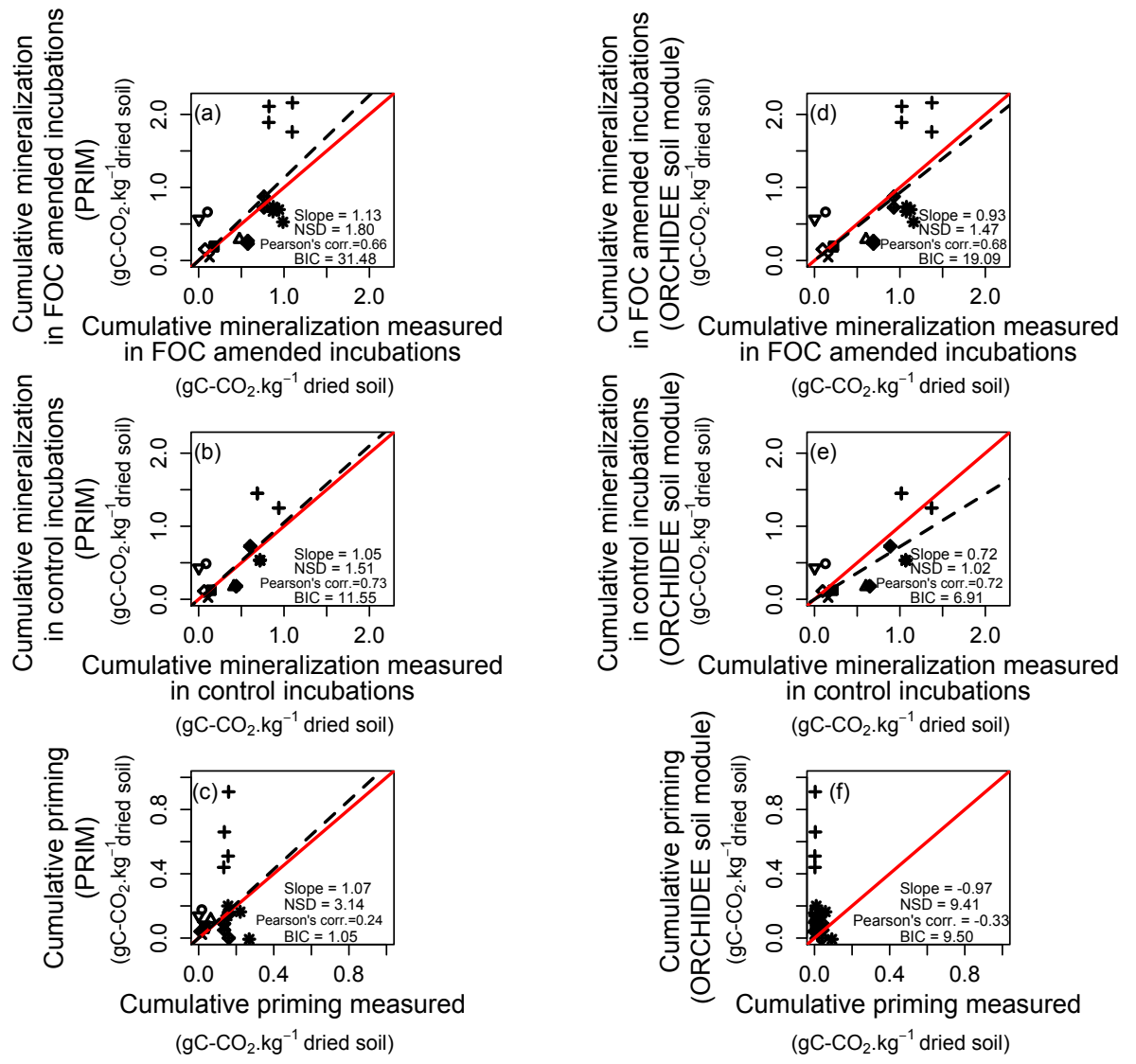

Figure 2. Scatter plot between data and the PRIM model outputs for the incubations with FOC amendment (a), without FOC amendment (b) and for priming effect (c). The data sets used here are the similar to those used for optimization (a) or are the control incubations (b) and are described in Sect. 2.2.1. Red lines indicate the $1: 1$ line. Different symbol indicate different studies.

similar performance as indicated by the values of slopes and NSD presented in Table 5. The mean slopes are 0.98 for ORCHIDEE-PRIM against 0.97 for ORCHIDEE, and the mean NSD are 1.26 and 1.27 , respectively. It must be noted that slope values were generally lower for the treatments excluding litter compared to control and double litter inputs (Table 5). No particular differences of the NSD values were observed between the different litter input regimes. Nevertheless, the BIC index was always higher for ORCHIDEEPRIM because three more parameters were used by this version compared to ORCHIDEE.

ORCHIDEE-PRIM was able to reproduce the priming observed defined as the difference of $\mathrm{CO}_{2}$ efflux coming from SOC only with or without litter (Fig. 5), but tended to underestimate its intensity as indicated by the slope value lower than 1 (0.55). The variance between experiments calculated for priming was overestimated as shown by the NSD value of 1.29. It must be noted that priming was not calculated for ORCHIDEE since the structure of its soil decomposition model does not include a priming mechanisms.

\section{Discussion}

\subsection{PRIM in the context of other soil priming conceptual models}

Priming is a complex phenomenon controlled by several mechanisms, such as $\mathrm{N}$ mining by microbial communities with different growth strategies, competition between microbial groups for substrate, energy limitations (Kuzyakov et al., 2000; Fontaine et al., 2003; Guenet et al., 2010b). Priming may have important consequences on the feedbacks between climate and C cycle (Schmidt et al., 2011) and it is therefore crucial to better quantify the $\mathrm{C}$ fluxes due to priming, especially at large scale (i.e. continental to global). Several models have been developed to describe soil $\mathrm{C}$ mineralization with a representation of priming (Gignoux et al., 2001; Fontaine and Barot, 2005; Neill and Gignoux, 2006; Moorhead and Sinsabaugh, 2006; Wutzler and Reichstein, 2008; Neill and Guenet, 2010; Blagodatsky et al., 2010) and such models generally succeeded at reproducing short-term data, mainly incubation. However, to our knowledge, they have never been tested in a range of contrasted situations (different 


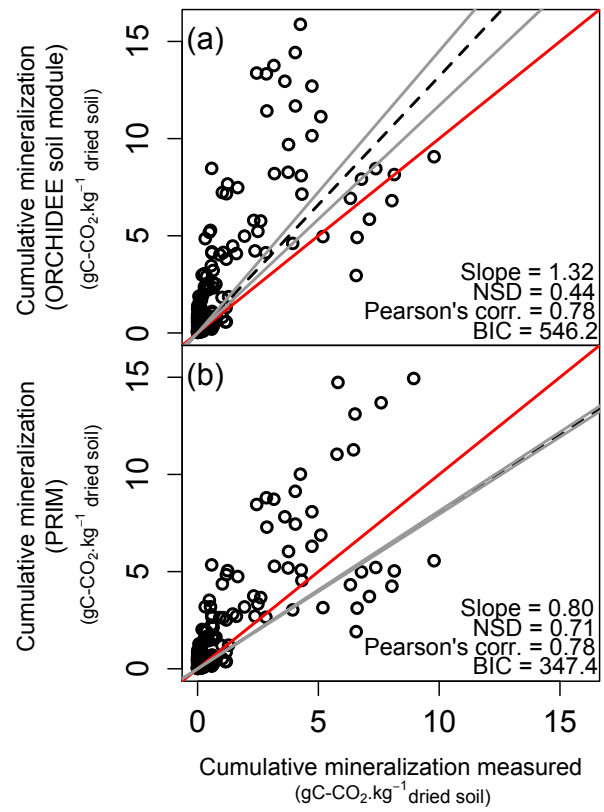

Figure 3. Scatter plot between independent data from optimization (data set describes in Sect. 2.2.2) and the soil module of ORCHIDEE outputs (a) or between data and the PRIM model outputs (b). Red lines indicate the 1: 1 line.

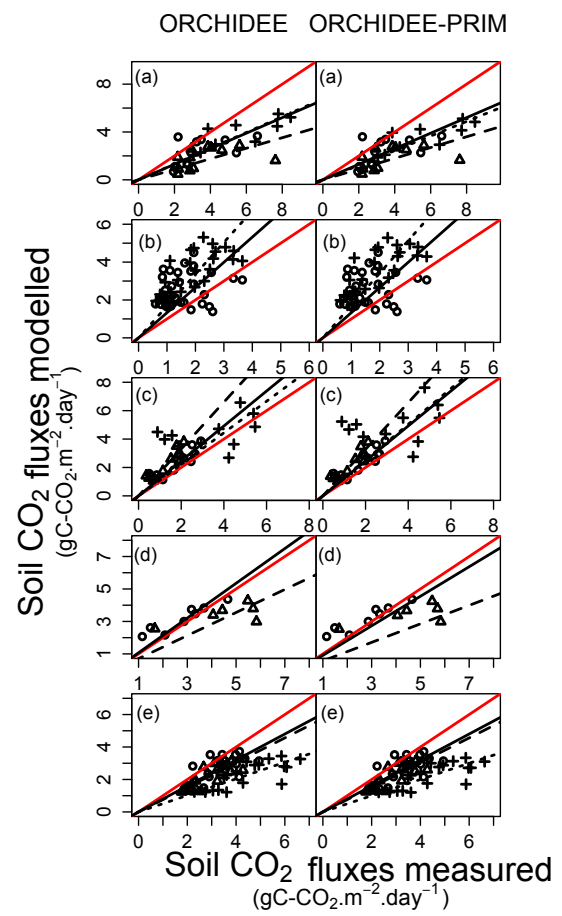

Figure 4. Soil $\mathrm{CO}_{2}$ efflux calculated by ORCHIDEE on the left side and by ORCHIDEE-PRIM on the right side for the data coming from Boone et al. (1998) (a), from Borken and Muhs (2002) (b), from Chemidlin-Prévost-Bourré et al. (2010) (c), from Subke et al. (2004) (d), and from Sulzman et al. (2005) (e). Red lines indicate the $1: 1$ line, black, dashed, and dotted lines correspond to control, litter exclusion, and litter amendment situations, respectively.

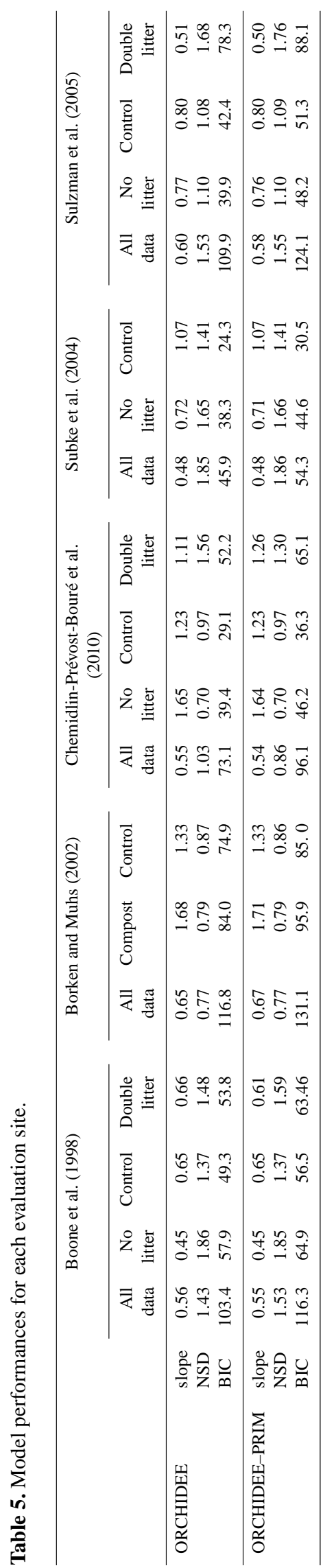

Geosci. Model Dev., 9, 841-855, 2016 


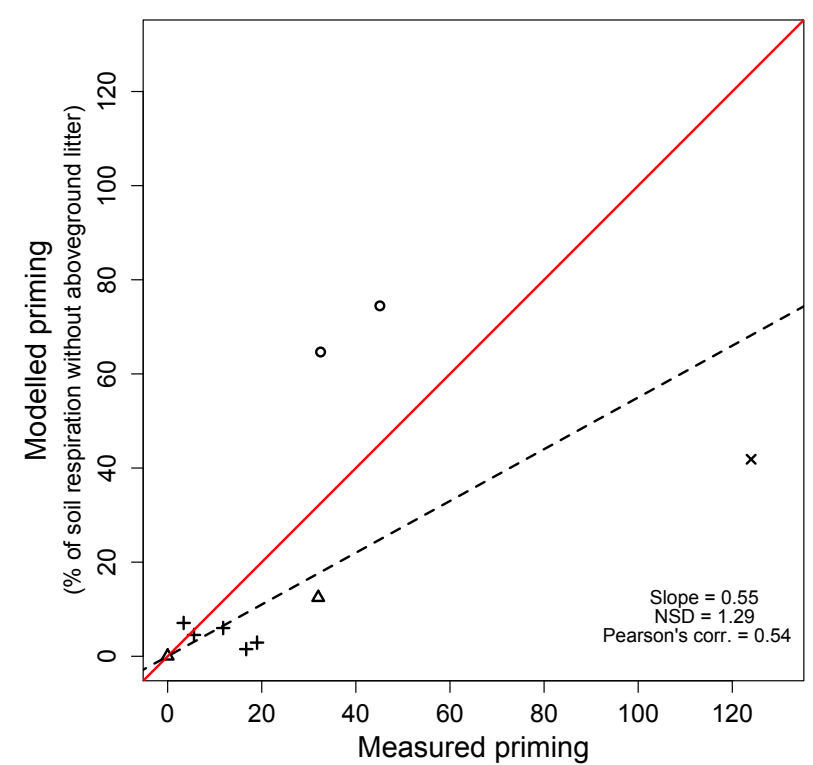

(\% of soil respiration without aboveground litter)

Figure 5. Scatter plot between the priming effect measured and the priming effect calculated by ORCHIDEE-PRIM. Red line indicates the $1: 1$ line and different symbols indicate different studies.

soil types, different FOC amount and chemical composition, different temperature and soil moisture, etc.). Here, we used most of the available incubation data respecting the criteria described in the material and method section. Moreover, previous priming models all needed a high number of parameters compared to PRIM. For these two reasons, the conceptual soil models accounting for soil priming were thus far not included in global land biosphere models (Wutzler and Reichstein, 2008) and very few studies of soil priming at global scale have been performed (Foereid et al., 2014). Here, using a simple scheme with only three more additional parameters than the standard soil module of ORCHIDEE, we were able to reproduce priming but also soil mineralization data coming from very different incubation studies performed with different soils at different temperature and moisture, with different time length, etc. The PRIM soil model, which is a microbial steady-state model, might not be able to reproduce short-term response to abrupt change of FOC inputs but with negligible bias over the long term (Wutzler and Reichstein, 2013). However, it might have similar performances than more complex models to reproduce long-term trends of FOC inputs (Wutzler and Reichstein, 2013). PRIM performed better than the standard soil module to reproduce soil incubation data used to optimize, but it must be noted that the BIC values indicate that the improvement observed with PRIM may be simply due to a higher number of parameters. Nevertheless, when using independent soil incubations data from the one used to optimize the model, the improvement is quite clear with BIC values much lower with PRIM than with the standard soil module (347.4 and 546.2, respectively). Fur- thermore, PRIM was not able to fully catch the observed variability of priming. As discussed above, priming is a complex phenomenon resulting from the interactions of different mechanisms that we summarized in a very simple equation. Therefore, PRIM is probably good in representing general trends but not all the complexity of the phenomenon. Nevertheless, the use of the PRIM soil model seems justified since it increases only slightly the number of parameter of a global land biosphere model and since the parameter values were obtained after optimization on data coming from incubations performed in a range of soils and conditions (different soil types, different ecosystems, different temperatures, different moisture, different amount and type of FOC amended, etc.).

\subsection{ORCHIDEE vs. ORCHIDEE-PRIM, Cross-sites evaluation}

ORCHIDEE-PRIM exhibited similar performance than ORCHIDEE when simulating litter manipulation experiments. It must be noted that both versions share the same scheme for primary production (controlling soil $\mathrm{C}$ input by litter), soil temperature, and moisture function. The similar performance obtained by the two versions may be due to a model bias for these quantities as well as poorly constrained site histories and climate forcing errors. Since primary production is the main driver of the $\mathrm{C}$ input into the soil, the soil $\mathrm{CO}_{2}$ efflux calculated by the models was largely driven by the capacity of the model to reproduce the observed primary production. In particular, both models largely underestimated the soil $\mathrm{CO}_{2}$ efflux when litter was removed (Table 5), but obtained good results when litter was kept or when litter was added. This suggests that both models performed quite well when reproducing soil $\mathrm{CO}_{2}$ efflux, but this was due to bias compensation, meaning that the fraction of $\mathrm{CO}_{2}$ coming from soil mineralization and root respiration was underestimated and the fraction of $\mathrm{CO}_{2}$ coming from litter mineralization was overestimated. Moreover, the modification of the litter cover may change the soil humidity and temperature and these effects were not represented in the models.

Finally, the use of a microbial steady-state model like ORCHIDEE-PRIM present some advantages compared to explicit microbial models. Wieder et al. (2013) identified several challenges related to the incorporation of explicit microbial models in ESMs. In particular, it needs many more parameters than the classical approach. With ORCHIDEEPRIM this difficulty is resolved since we only add three more parameters.

\section{Conclusion}

With regard to the various processes that may lead to priming, the satisfactory performance of ORCHIDEE-PRIM compared to observations from both laboratory incubation and field litter manipulation experiments suggests that the 
simple PRIM conceptual model simulates well the magnitude of observed priming. Consequently, ORCHIDEEPRIM has the potential to quantify the impact of priming on the soil $\mathrm{C}$ cycle at large scales. Nevertheless, ORCHIDEEPRIM underestimates the priming intensity as shown by the slope value (0.55), indicating that the model still misses important mechanisms explaining the observations. In particular, $\mathrm{N}$ availability is an important driver of priming, inducing higher priming when $\mathrm{N}$ availability is reduced (Fontaine et al., 2004b; Blagodatskaya et al., 2007). The role of $\mathrm{N}$ in the priming intensity as well as the extra $\mathrm{N}$ mineralization induced by priming and its effect on primary production may represent the next addition to the soil representation in a land surface model by adding a control on the $c$ parameter depending on the mineral $\mathrm{N}$ availability and on the $\mathrm{C}: \mathrm{N}$ ratio of the considered pool. Nevertheless, some detailed information on the $\mathrm{N}$ dynamic in priming effect experiments would be necessary to do so and very few authors reported the impact of the priming effect on the $\mathrm{N}$ dynamic after FOC additions.

\section{Code availability}

For ORCHIDEE, the main part of the code was written by Krinner et al. (2005). The version used here is the 1.9.5.2 version. In this version, compared to the one presented in Krinner et al. (2005), the albedo representation was improved (http://dods.ipsl.jussieu.fr/orchidee/ DOXYGEN/webdoc_1240/), a routing scheme controlling the flux of water from land surface to the ocean was added (Ngo-Duc et al., 2007) and the dynamic of vegetation was modified (http://dods.ipsl.jussieu.fr/orchidee/ DOXYGEN/webdoc_1240/). Furthermore, since 2005 the code has been parallelized. A detailed documentation and the code can be provided upon request to the corresponding author.

ORCHIDEE-PRIM is derived from ORCHIDEE with the modifications presented in Sect. 2.1.2. A detailed description can be found in Guenet et al. (2013b). The code is available upon request to the corresponding author.

Edited by: C. Sierra

\section{References}

Bell, J., Smith, J., Bailey, V., and Bolton, H.: Priming effect and C storage in semi-arid no-till spring crop rotations, Biol. Fert. Soils, 37, 237-244, 2003.

Bellamy, P. H., Loveland, P. J., Bradley, R. I., Lark, R. M., and Kirk, G. J. D.: Carbon losses from all soils across England and Wales 1978-2003, Nature, 437, 245-248, 2005.

Blagodatskaya, E. and Kuzyakov, Y.: Mechanisms of real and apparent priming effects and their dependence on soil microbial biomass and community structure: critical review, Biol. Fert. Soils, 45, 115-131, 2008.
Blagodatskaya, E. V., Blagodatsky, S. A., Anderson, T.-H., and Kuzyakov, Y.: Priming effects in chernozem induced by glucose and $\mathrm{N}$ in relation to microbial growth strategies, Appl. Soil Ecol., 37, 95-105, 2007.

Blagodatsky, S. A. and Richter, O.: Microbial growth in soil and nitrogen turnover: a theoretical model considering the activity state of microorganisms, Soil Biol. Biochem., 30, 1743-1755, 1998.

Blagodatsky, S. A., Blagodatskaya, E., Yuyukina, T., and Kuzyakov, Y.: Model of apparent and real priming effects: Linking microbial activity with soil organic matter decomposition, Soil Biol. Biochem., 42, 1275-1283, 2010.

Boone, R., Nadelhoffer, K., and Canary, J.: Roots exert a strong influence on the temperature sensitivity of soil respiration, Nature, 396, 570-572, 1998.

Borken, W. and Muhs, A.: Application of compost in spruce forests: effects on soil respiration, basal respiration and microbial biomass, Forest Ecol. Manag., 159, 49-58, 2002.

Chemidlin Prévost-Bouré, N., Soudani, K., Damesin, C., Berveiller, D., Lata, J.-C., and Dufrêne, E.: Increase in aboveground fresh litter quantity over-stimulates soil respiration in a temperate deciduous forest, Appl. Soil Ecol., 46, 26-34, 2010.

Ciais, P., Reichstein, M., Viovy, N., Granier, A., Ogée, J., Allard, V., Aubinet, M., Buchmann, N., Bernhofer, C., Carrara, A., Chevallier, F., De Noblet, N., Friend, A. D., Friedlingstein, P., Grünwald, T., Heinesch, B., Keronen, P., Knohl, A., Krinner, G., Loustau, D., Manca, G., Matteucci, G., Miglietta, F., Ourcival, J. M., Papale, D., Pilegaard, K., Rambal, S., Seufert, G., Soussana, J. F., Sanz, M. J., Schulze, E. D., Vesala, T., and Valentini, R.: Europewide reduction in primary productivity caused by the heat and drought in 2003, Nature, 437,529-533, 2005.

Cleveland, C. C., Nemergut, D. R., Schmidt, S. K., and Townsend, A. R.: Increases in soil respiration following labile carbon additions linked to rapid shifts in soil microbial community composition, Biogeochemistry, 82, 229-240, 2007.

Coleman, K. and Jenkinson, D. S.: RothC-26.3, A Model for the Turnover of Carbon in Soil: Model Description and User's Guide, Lawes Agric. Trust, Harpenden, UK, 1999.

Conde, E., Cardenas, M., Poncemendoza, A., Lunaguido, M., Cruzmondragon, C., and Dendooven, L.: The impacts of inorganic nitrogen application on mineralization of C-labelled maize and glucose, and on priming effect in saline alkaline soil, Soil Biol. Biochem., 37, 681-691, 2005.

De Nobili, M., Contin, M., and Mondini, C.: Soil microbial biomass is triggered into activity by trace amounts of substrate, Soil Biol. Biochem., 33, 1163-1170, 2001.

de Rosnay, P. and Polcher, J.: Modelling root water uptake in a complex land surface scheme coupled to a GCM, Hydrol. Earth Syst Sci., 2, 239-255, doi:10.5194/hess-2-239-1998, 1998.

Ducoudré, N. I., Laval, K., and Perrier, A.: SECHIBA, a new set of parameterizations of the hydrologic exchanges at the landatmosphere interface within theLMDatmospheric general circulation model, J. Climate, 6, 248-273, 1993.

Falchini, L., Naumova, N., Kuikman, P. J., Bloem, J., and Nannipieri, P.: $\mathrm{CO}_{2}$ evolution and denaturing gradient gel electrophoresis profiles of bacterial communities in soil following addition of low molecular weight substrates to simulate root exudation, Soil Biol. Biochem., 35, 775-782, 2003. 
Foereid, B., Ward, D. S., Mahowald, N., Paterson, E., and Lehmann, J.: The sensitivity of carbon turnover in the Community Land Model to modified assumptions about soil processes, Earth Syst. Dynam., 5, 211-221, doi:10.5194/esd-5-211-2014, 2014.

Fontaine, S. and Barot, S.: Size and functional diversity of microbe populations control plant persistence and long-term soil carbon accumulation, Ecol. Lett., 8, 1075-1087, 2005.

Fontaine, S., Mariotti, A., and Abbadie, L.: The priming effect of organic matter: a question of microbial competition?, Soil Biol. Biochem., 35, 837-843, 2003.

Fontaine, S., Bardoux, G., and Benest, D.: Mechanisms of the priming effect in a savannah soil amended with cellulose, Soil Sci. Soc. Am. J., 68, 125-131, 2004a.

Fontaine, S., Bardoux, G., Abbadie, L., and Mariotti, A.: Carbon input to soil may decrease soil carbon content, Ecol. Lett., 7, 314320, 2004b.

Friedlingstein, P., Cox, P., Betts, R., Bopp, L., Von Bloh, W., Brovkin, V., Cadule, P., Doney, S., Eby, M., Fung, I., Bala, G., John, J., Jones, C., Joos, F., Kato, T., Kawamiya, M., Knorr, W., Lindsay, K., Matthews, H. D., Raddatz, T., Rayner, P., Reick, C., Roeckner, E., Schnitzler, K. G., Schnur, R., Strassmann, K., Weaver, A. J., Yoshikawa, C., and Zeng, N.: Climate- carbon cycle feedback analysis: results from the C4MIP model intercomparison, J. Climate, 19, 3337-3353, 2006.

Garcia-Pausas, J. and Paterson, E.: Microbial community abundance and structure are determinants of soil organic matter mineralisation in the presence of labile carbon, Soil Biol. Biochem., 43, 1705-1713, 2011.

Gignoux, J., House, J., Hall, D., Masse, D., Nacro, H. B., and Abbadie, L.: Design and test of a generic cohort model of soil organic matter decomposition: the SOMKO model, Global Ecol. Biogeogr., 10, 639-660, 2001.

Guenet, B., Neill, C., Bardoux, G., and Abbadie, L.: Is there a linear relationship between priming effect intensity and the amount of organic matter input?, Appl. Soil Ecol., 46, 436-442, 2010a.

Guenet, B., Danger, M., Abbadie, L., and Lacroix, G.: Priming effect: bridging the gap between terrestrial and aquatic ecology, Ecology, 91, 2850-2861, 2010b.

Guenet, B., Juarez, S., Bardoux, G., Luc, A., and Claire, C.: Evidence that stable $\mathrm{C}$ is as vulnerable to priming effect as is more labile C in soil, Soil Biol. Biochem., 52, 43-48, 2012.

Guenet, B., Eglin, T., Vasilyeva, N., Peylin, P., Ciais, P., and Chenu, C.: The relative importance of decomposition and transport mechanisms in accounting for soil organic carbon profiles, Biogeosciences, 10, 2379-2392, doi:10.5194/bg-10-2379-2013, 2013a.

Guenet, B., Moyano, F. E., Vuichard, N., Kirk, G. J. D., Bellamy, P. H., Zaehle, S., and Ciais, P.: Can we model observed soil carbon changes from a dense inventory? A case study over England and Wales using three versions of the ORCHIDEE ecosystem model (AR5, AR5-PRIM and O-CN), Geosci. Model Dev., 6, 21532163, doi:10.5194/gmd-6-2153-2013, 2013b.

Hamer, U. and Marschner, B.: Priming effects in different soil types induced by fructose, alanine, oxalic acid and catechol additions, Soil Biol. Biochem., 37, 445-454, 2005.

Hararuk, O., Xia, J., and Luo, Y.: Evaluation and improvement of a global land model against soil carbon data using a Bayesian Markov chain Monte Carlo method, J. Geophys. Res.-Biogeo., 119, 403-417, 2014.
Jones, C. D., Cox, P., and Huntingford, C.: Uncertainty in climatecarbon-cycle projections associated with the sensitivity of soil respiration to temperature, Tellus B, 55, 642-648, 2003.

Kalnay, E., Kanamitsu, M., Kistler, R., Collins, W., Deaven, D., Gandin, L., Iredell, M., Saha, S., White, G., Woollen, J., Zhu, Y., Chelliah, M., Ebisuzaki, W., Higgins, W., Janowiak, J., Mo, K. C., Ropelewski, C., Wang, J., Leetmaa, A., Reynolds, R., Jenne, R., and Joseph, D.: The NCEP/NCAR 40-year reanalysis project, B. Am. Meteorol. Soc., 77, 437-470, 1996.

Kemmitt, S. J., Lanyon, C. V., Waite, I. S., Wen, Q., Addiscott, T. M., Bird, N. R. A., O’Donnell, A. G., and Brookes, P. C.: Mineralization of native soil organic matter is not regulated by the size, activity or composition of the soil microbial biomass - a new perspective, Soil Biol. Biochem., 40, 61-73, 2008.

Krinner, G., Viovy, N., de Noblet-Ducoudré, N., Ogée, J., Polcher, J., Friedlingstein, P., Ciais, P., Sitch, S., and Prentice, I. C.: A dynamic global vegetation model for studies of the coupled atmosphere-biosphere system, Global Biogeochem. Cy., 19, GB1015, doi:10.1029/2003GB002199, 2005.

Kuzyakov, Y., Friedel, J. K., and Stahr, K.: Review of mechanisms and quantification of priming effects, Soil Biol. Biochem., 32, 1485-1498, 2000.

Luo, Y., Ahlström, A., Allison, S. D., Batjes, N. H., Brovkin, V., Carvalhais, N., Chappell, A., Ciais, P., Davidson, E. A., Finzi, A., Georgiou, K., Guenet, B., Hararuk, O., Harden, J. W., He, Y., Hopkins, F., Jiang, L., Koven, C., Jackson, R. B., Jones, C. D., Lara, M. J., Liang, J., McGuire, D., Parton, W., Peng, C., Randerson, J. T., Salazar, A., Sierra, C. A., Smith, M. J., Tian, H., Todd-Brown, K. E. O., Torn, M., van Groenigen, K. J., Wang, Y. P., West, T. O., Wei, Y., Wieder, W. R., Xia, J., Xu, X., Xu, X., and Zhou, T.: Towards More Realistic Projections of Soil Carbon Dynamics by Earth System Models, Global Biogeochem. Cy., 30, 40-56, doi:10.1002/2015GB005239, 2016.

Manzoni, S. and Porporato, A.: Soil carbon and nitrogen mineralization: Theory and models across scales, Soil Biol. Biochem., 41, 1355-1379, 2009.

MEA: Millennium Ecosystem Assessment - Nutrient Cycling, World Resource Institute, Washington, D.C., USA, 2005.

Mitchell, T. D., Carter, T. R., Jones, P. D., Hulme, M., and New, M.: A Comprehensive Set of High-Resolution Grids of Monthly Climate for Europe and the Globe: The Observed Record (19012000) and 16 Scenarios (2001-2100), 33 pp., Tyndall Center for Climate Change Research, University of East Anglia, Norwich, UK, 2004.

Moorhead, D. L. and Sinsabaugh, R. L.: A theoretical model of litter decay and microbial interaction, Ecol. Monogr., 76, 151-174, 2006.

Moyano, F. E., Vasilyeva, N., Bouckaert, L., Cook, F., Craine, J., Curiel Yuste, J., Don, A., Epron, D., Formanek, P., Franzluebbers, A., Ilstedt, U., Kätterer, T., Orchard, V., Reichstein, M., Rey, A., Ruamps, L., Subke, J.-A., Thomsen, I. K., and Chenu, C.: The moisture response of soil heterotrophic respiration: interaction with soil properties, Biogeosciences, 9, 1173-1182, doi:10.5194/bg-9-1173-2012, 2012.

Neill, C. and Gignoux, J.: Soil organic matter decomposition driven by microbial growth: a simple model for a complex network of interactions, Soil Biol. Biochem., 38, 803-811, 2006. 
Neill, C. and Guenet, B.: Comparing two mechanistic formalisms for soil organic matter dynamics: A test with in vitro priming effect observations, Soil Biol. Biochem., 42, 1212-1221, 2010.

Ngo-Duc, T., Laval, K., Ramillien, G., Polcher, J., and Cazenave, A.: Validation of the land water storage simulated by Organising Carbon and Hydrology in Dynamic Ecosystems (ORCHIDEE) with Gravity Recovery and Climate Experiment (GRACE) data, Water Resour. Res., 43, W04427, doi:10.1029/2006WR004941, 2007.

Panikov, N. S. and Sizova, M. V.: A kinetic method for estimating the biomass of microbial functional groups in soil, J. Microbiol. Meth., 24, 219-230, 1996.

Parton, W. J., Stewart, J. W. B., and Cole, C. V.: Dynamics of C, N, $\mathrm{P}$ and $\mathrm{S}$ in grassland soils - a model, Biogeochemistry, 5, 109131, 1988

Piao, S. L., Friedlingstein, P., Ciais, P., Zhou, L., and Chen, A.: Effect of climate and $\mathrm{CO}_{2}$ changes on the greening of the Northern Hemisphere over the past two decades, Geophys. Res. Lett., 33, L23402, doi:10.1029/2006GL028205, 2006.

Rodale, J. I., Rodale, R., Olds, J., Goldman, M. C., Franz, M., and Minnich, J.: The complete book of composting, Rodale Books, Emmaus, Pennsylvania, USA, 1960.

Santaren, D., Peylin, P., Viovy, N., and Ciais, P.: Optimizing a process-based ecosystem model with eddy-covariance flux measurements: A pine forest in southern France, Global Biogeochem. Cy., 21, GB2013, doi:10.1029/2006GB002834, 2007.

Santaren, D., Peylin, P., Bacour, C., Ciais, P., and Longdoz, B.: Ecosystem model optimization using in situ flux observations: benefit of Monte Carlo versus variational schemes and analyses of the year-to-year model performances, Biogeosciences, 11, 7137-7158, doi:10.5194/bg-11-7137-2014, 2014.

Schmidt, M. W. I., Torn, M. S., Abiven, S., Dittmar, T., Guggenberger, G., Janssens, I., Kleber, M., Kögel-Knabner, I., Lehmann, J., Manning, D. C., Nannipieri, P., Rasse, D. P., Weiner, S., and Trumbore, S. E.: Persistence of soil organic matter as an ecosystem property, Nature, 478, 49-56, 2011.

Sitch, S., Huntingford, C., Gedney, N., Levy, P. E., Lomas, M., Piao, S. L., Betts, R., Ciais, P., Cox, P., Friedlingstein, P., Jones, C. D., Prentice, I. C., and Woodward, F. I.: Evaluation of the terrestrial carbon cycle, future plant geography and climate-carbon cycle feedbacks using five Dynamic Global Vegetation Models (DGVMs), Glob. Change Biol., 14, 2015-2039, 2008.
Six, J., Conant, R., Paul, E., and Paustian, K.: Stabilization mechanisms of soil organic matter: Implications for C-saturation of soils, Plant Soil, 241, 155-176, 2002.

Subke, J.-A., Hahn, V., Battipaglia, G., Linder, S., Buchmann, N., and Cotrufo, M. F.: Feedback interactions between needle litter decomposition and rhizosphere activity, Oecologia, 139, 551559, 2004.

Sulzman, E. W., Brant, J. B., Bowden, R. D., and Lajtha, K.: Contribution of aboveground litter, belowground litter, and rhizosphere respiration to total soil $\mathrm{CO}_{2}$ efflux in an old growth coniferous forest, Biogeochemistry, 73, 231-256, 2005.

Tarantola, A.: Inverse Problem Theory: Methods of Data Fitting and Model Parameter Estimation, Elsevier Science Ltd., New York, USA, 630 pp., 1987.

Todd-Brown, K. E. O., Randerson, J. T., Post, W. M., Hoffman, F. M., Tarnocai, C., Schuur, E. A. G., and Allison, S. D.: Causes of variation in soil carbon simulations from CMIP5 Earth system models and comparison with observations, Biogeosciences, 10, 1717-1736, doi:10.5194/bg-10-1717-2013, 2013.

Wieder, W. R., Bonan, G. B., and Allison, S. D.: Global soil carbon projections are improved by modelling microbial processes, Nature Climate Change, 3, 1-4, 2013.

Wutzler, T. and Reichstein, M.: Colimitation of decomposition by substrate and decomposers - a comparison of model formulations, Biogeosciences, 5, 749-759, doi:10.5194/bg-5-749-2008, 2008.

Wutzler, T. and Reichstein, M.: Priming and substrate quality interactions in soil organic matter models, Biogeosciences, 10, 2089 2103, doi:10.5194/bg-10-2089-2013, 2013.

Xiao, C., Guenet, B., Zhou, Y., Su, J., and Janssens, I. A.: Priming of soil organic matter decomposition scales linearly with microbial biomass response to litter input in steppe vegetation, Oikos, 124, 649-657, 2015.

Zhu, C., Byrd, R. H., Lu, P., and Nocedal, J.: A limited memory algorithm for bound constrained optimisation, SIAM J. Sci. Stat Comp., 16, 1190-1208, 1995.

Zobler, L.: A World Soil File for Global Climate Modeling, Technical Memorandum 87802, NASA Goddard Institute for Space Studies (GISS), New York, NY, USA, 1986. 